\title{
Enhancement of the Product Information Collaboration and Access in the Aerospace Industry
}

\author{
E. Shehab ${ }^{1}$, C. Fowler ${ }^{2}$, A. Rodriguez Gil ${ }^{3}$, H. Abdalla ${ }^{1}$, M. Darwish ${ }^{1}$, H. Abdulhafed ${ }^{1}$, A. Ahmed ${ }^{1}$, H. \\ Ahouie $^{4}$, A. Alechnovic ${ }^{1}$, C. Paumes ${ }^{1}$, E. Tacchini ${ }^{1}$, I. Urbane ${ }^{1}$, M. Richardson ${ }^{2}$ \\ ${ }^{1}$ Manufacturing and Materials Department, Cranfield University, Cranfield, Bedfordshire, MK43 OAL, UK \\ ${ }^{2}$ Airbus Operations Ltd, Filton, Bristol, Avon BS99 7AR, UK \\ ${ }^{3}$ Accenture, Madrid, Spain \\ ${ }^{4}$ Aston Martin, Banbury Road, Gaydon, Warwick, CV35 0DB, UK
}

\begin{abstract}
This paper presents the development of four scenarios to design a pull mode industrial solution that enables tier-one suppliers to securely and efficiently retrieve data for manufacturing purposes from Original Equipment Manufacturers (OEMs). The research aims to facilitate and enhance product information sharing between OEMs and their Tierone suppliers. The proposed scenarios were developed using PDMLink, which is a Product Lifecycle management system (PLM) and Microsoft SharePoint collaboration platform. The research methodology comprises seven phases including definition of scope, understanding the AS-IS processes, gap analysis, development of the scenarios, and finally validation and cost analysis. This methodology was implemented to select the most suitable scenario for utilising the tools available in the PLM system to accomplish the pull mode data collaboration solution. The data for this research was collected in a number of ways including semi-structured interviews, workshops with experts, and reviews of technical documentation on current processes.
\end{abstract}

The major benefits of the developed solution are: cost reduction due to diminution of resources required for the new process; lead time to access data by suppliers and improved data management. These will reduce the product development cycle, and ensure improved quality of manufactured components.

Keywords: Product Development; Data Sharing; Collaboration; Risk Sharing Partners (RSPs) 


\section{Introduction}

Risk sharing partners (RSPs) have been playing a significant role in the aerospace sector in recent years. Their importance is backed up by tight collaboration with original equipment manufacturers (OEMs) during design and manufacturing stages. OEMs are steering away from manufacturing components for aircraft and are focusing mostly on systems integration, and research and development of new technologies. Previously, suppliers were in charge of manufacturing activities only. Nowadays, they are also given responsibility to design components and assemblies for the aircraft. Therefore, OEMs and RSPs share actual risk during design and development activities.

Over the last few years, strong relationships have been formed between both parties, and risk sharing partners are closely integrated within the OEM's processes and infrastructure. As a result of the multinational collaboration between enterprises, OEMs are required to improve or re-structure their information systems and information technologies to support data sharing operations and processes (Figuereido et al, 2008). One of the main difficulties for OEMs is their limited ability to harmonise data flows and synchronise different types of data for RSPs.

To facilitate appropriate data exchange channels, an OEM should be able to collaborate with an RSP effectively. Providing the required data at the right time in the right place is an essential requirement. Lean communication is a key factor to enable this collaboration (Garnsey, 2001). An ideal way of achieving this would be through the introduction of an effective pull mode system for data retrieval. RSPs should have timely access to the data they require. In the aerospace industry, large amounts of engineering data are produced on an hourly basis. Due to the technical limitations and complexity involved, OEMs tend to use intermediate data storages which duplicate information.

This research project is carried out in collaboration between Airbus and Cranfield University, both of whom are in the UK. The focus of the study is to examine optimal ways of exchanging design and manufacturing data for RSPs. Particular attention is given to the metadata and geometrical data and their synchronisation. In addition, process harmonisation aspects were investigated to achieve better information sharing using secure role based access to avoid any improper use of information. Therefore the intention 
of this research is to consolidate a strong and mutual beneficial relationship among OEMs and their Risk sharing partners (RSPs).

The remainder of the paper is comprised of six main sections. IThe literature review details common definitions and summarises previous research, Section 3 describes the methodology adopted in the research project. Further sections analyse current issues and examine scenario solutions. The validation section of this paper details the evaluation of the scenario solutions by industry specialists. The findings of this research were critically evaluated to provide objective opinion and areas for further investigation are proposed.

\section{Literature Review and Research Scope}

A collaboration system represents infrastructure of the interdependent tools, applications and systems. Product Lifecycle Management (PLM) takes care of the entire life of each product from the design to the disposal stage (Tomovic et al 2010; Rosen; Frillman et al., 2010). There are various acronyms and descriptions which comprise the PLM definition, and can lead to confusion, especially for customers. (Abramovici et al., 2002). Some of these are; Collaborative Product Development (cPDM), Collaborative Product Commerce (CPC), 3D Product Lifecycle Management (3D-PLM), Product Knowledge Management (PKM), or Virtual Product Development (VPDM).

The architectures of these distributed collaborative systems can be generally grouped into two main approaches which are web-based collaborative systems and agent-based collaborative systems (Shen et al., 2008). A web-based collaborative system typically uses a client-server architecture. The geometry kernel can be stored in each client, while the server acts as an information agent and distributes the CAD models (thick client-thin server). Due to the heavyweight client mechanism, it is hard to migrate to a web- based application generated by one client to other clients. Hence the other mechanism is to store the geometry kernel in the server (thin client-thick server), each client can then get access accordingly using web-based technology (Fan at al., 2008). In agent-based collaborative systems, software tools are being used for supporting co-operation among designers, providing the semantic glue between traditional tools, or for allowing better simulations (Fan et al., 2007). Such an agent based system is best described as a loosely coupled network of problem solvers (Shen et al., 2008). Most agent-based systems utilise a Peer to Peer architecture (Fan et al., 2008) 
Both agent and web-based technologies are very useful in implementing collaborative design systems. The attractiveness of the Web for propagating information makes it appropriate to integrate with agents for accessing and manipulating information automatically (Shen et al., 2008). Client-server and peer to peer approaches can be integrated in a hybrid approach as illustrated in Figure 1. The web-based servers act as super peers to extend the peer to peer network (Fan et al., 2008)

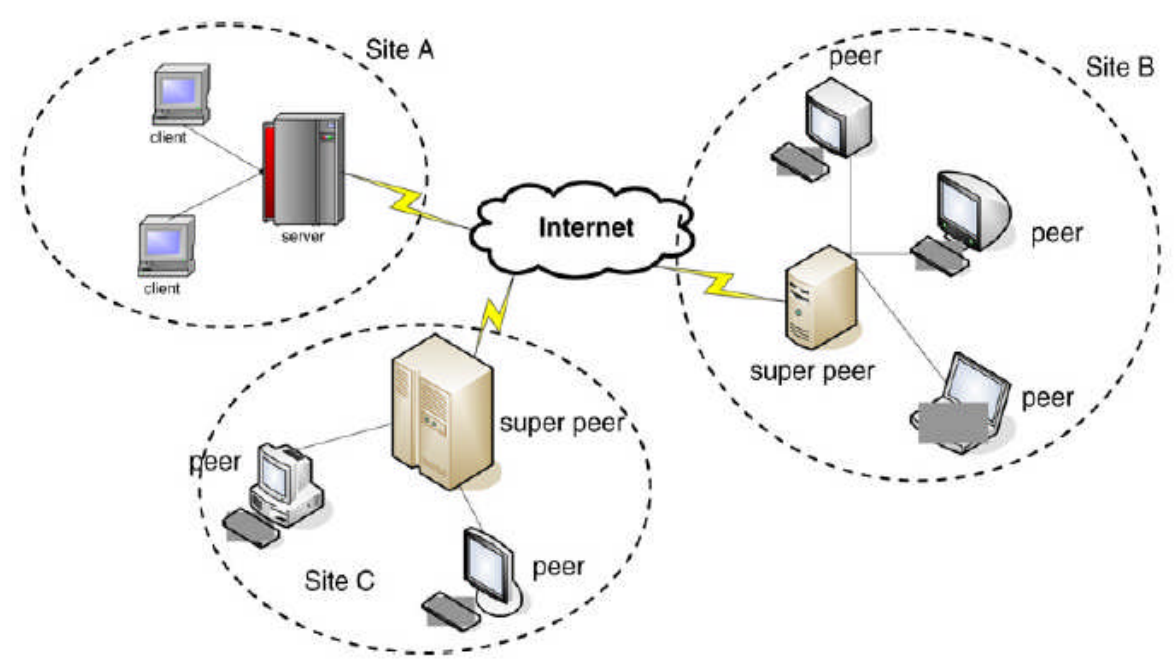

Figure 1: Collaborative system with hybrid approach (Fan et al., 2008)

According to Baker (1999), a PDM system can be used to follow a PLM process and act as a central data repository. It ensures that product data is managed according to both configuration management and change management principles. Many distributed computing systems have been built to support the collaborative design modelling and decision-making process (Zha and $\mathrm{Du}, 2006$ ). Such systems promised that the "right information" is provided to the "right person" at the "right time" in the "right order" (Shen et al., 2008). Based on Zha and Du (2006), collaborative systems can be grouped into the following categories: (i) Collaborative product data/information management systems for engineers to obtain the necessary product data and knowledge in a timely manner; (ii) Network-based collaborative design systems, which can be further divided into webindependent and web-dependent systems; (iii) Process-centred collaborative design and workflow management systems; (iv) Conflict detection, management and resolution systems for collaborative design; (v) Flexible security focused collaborative design systems; (vi) Interoperability approaches in heterogeneous collaborative design systems. 
Many commercial software packages offer solutions based on various platforms and architectures as illustrated in Table 1 (Zha and Du, 2006), hence choosing the proper system is an important strategic decision as it depends on the degree of the system's integration with other tools and legacy systems (Storga et al., 2001). Some of the mainstream solutions include UGS TeamCenter, PTC Windchill,and ENOVIA VPLM, (Shen et al., 2008).

\begin{tabular}{|c|c|c|c|c|c|c|}
\hline System & Architecture & Platform & Communication & $\begin{array}{l}\text { Collaboration } \\
\text { granularity }\end{array}$ & $\begin{array}{l}\text { Network } \\
\text { burden }\end{array}$ & $\begin{array}{l}\text { Modelling } \\
\text { technique }\end{array}$ \\
\hline DICE & Centralised & $\begin{array}{l}\text { Motif } \\
\text { Compatible } \\
\text { Unix } \\
\text { Windows }\end{array}$ & $\begin{array}{l}\text { Specialised Messaging \& } \\
\text { Collaboration (OODMS) }\end{array}$ & Fine & Heavy & $\begin{array}{l}\text { 2D/3D } \\
\text { parametric } \\
\text { surface/solid } \\
\text { modelling }\end{array}$ \\
\hline Alibre & Centralised & PC Windows & $\begin{array}{l}\text { TCP/IP, DirectX DSL, } \\
\text { Cable Modem, TI or faster }\end{array}$ & Coarse & Light & $\begin{array}{l}\text { 2D/3D } \\
\text { parametric solid } \\
\text { modelling }\end{array}$ \\
\hline $\begin{array}{l}\text { Co-Create } \\
(\text { OneSpace.Net) }\end{array}$ & Centralised & PC Windows & Microsoft.NET & Fine & Light & $\begin{array}{l}\text { 2D/3D solid } \\
\text { modelling }\end{array}$ \\
\hline NetPrise & Centralised & PC Windows & $\begin{array}{l}\text { Specialised } \\
\text { Messaging/Collaboration } \\
\text { Hub }\end{array}$ & Coarse & Light & Solid modelling \\
\hline Windchill (PTC) & Centralised & $\begin{array}{l}\text { PC Windows } \\
\text { NT, Unix } \\
\text { Workstation }\end{array}$ & Java RMI, XML & Coarse & Light & $\begin{array}{l}\text { Feature-based } \\
\text { modelling }\end{array}$ \\
\hline $\begin{array}{l}\text { Teamcentre } \\
\text { (UGS) }\end{array}$ & Centralised & $\begin{array}{l}\text { PC Windows } \\
\text { NT, Unix } \\
\text { Workstation }\end{array}$ & $\begin{array}{l}\text { Microsoft.NET, J2EE } \\
\text { UDDI, SOAP, XML, JSP } \\
\text { Communication Service }\end{array}$ & Coarse & Light & $\begin{array}{l}\text { Parametric, } \\
\text { Feature-based } \\
\text { modelling }\end{array}$ \\
\hline CollaCAD & Centralised & $\begin{array}{l}\text { PC Windows, } \\
\text { Intel Linux }\end{array}$ & Java RMI, Java3D & Coarse & Heavy & $\begin{array}{l}\text { Surface } \\
\text { modelling, solid } \\
\text { modelling }\end{array}$ \\
\hline CyberCAD & Centralised & $\begin{array}{l}\text { Platform } \\
\text { independent }\end{array}$ & Point-Point Java RMI & Fine & Heavy & Solid Modelling \\
\hline NetFeature & Centralised & PC Windows & $\begin{array}{l}\text { COBRA Communicate } \\
\text { Service }\end{array}$ & Coarse & Heavy & $\begin{array}{l}\text { Feature-based } \\
\text { modelling }\end{array}$ \\
\hline WebSPIFF & Centralised & PC Windows & Java 3D Socket & Fine & Heavy & $\begin{array}{l}\text { Feature-based } \\
\text { modelling }\end{array}$ \\
\hline $\begin{array}{l}\text { Cooperative } \\
\text { ARCADE }\end{array}$ & Decentralised & $\begin{array}{l}\text { SGI, HP, } \\
\text { SUN } \\
\text { Workstation }\end{array}$ & $\begin{array}{l}\text { Specialised Workstation } \\
\text { Network }\end{array}$ & Coarse & Light & Solid Modelling \\
\hline $\begin{array}{l}\text { CSCW- } \\
\text { FeatureM }\end{array}$ & Decentralised & $\begin{array}{l}\text { Motif } \\
\text { Compatible } \\
\text { Unix } \\
\text { Windows } \\
\end{array}$ & $\begin{array}{l}\text { COBRA communication } \\
\text { Service }\end{array}$ & Fine & Light & $\begin{array}{l}\text { Feature-based } \\
\text { modelling }\end{array}$ \\
\hline TOBACO & Decentralised & $\begin{array}{l}\text { Solaris IRIX, } \\
\text { Windows NT }\end{array}$ & $\begin{array}{l}\text { COBRA communication } \\
\text { Service }\end{array}$ & Fine & Light & $\begin{array}{l}\text { Solid/Feature } \\
\text { modelling }\end{array}$ \\
\hline DOME & Decentralised & $\begin{array}{l}\text { Platform } \\
\text { independent }\end{array}$ & $\begin{array}{l}\text { COBRA communication } \\
\text { Service }\end{array}$ & Coarse & Light & $\begin{array}{l}\text { Module } \\
\text { modelling }\end{array}$ \\
\hline
\end{tabular}

Table 1: Overview of different collaborative systems (Zha and Du, 2006) 
For effective design and manufacturing collaboration processes between RSPs and OEMs, it is required to allocate specific roles and permissions. Role based access plays a significant part in tracking user activity (Zhiming et al., 2006; Müldner et al., 2009; Masood et al., 2009; Bouna et al., 2009). Further investigation indicated that PDM helps design engineers to manage the product data and product development process, and Enterprise Resource Planning (ERP) is important in managing orders, production and inventory processes. It has been noticed that the integration of ERP with PDM can bring number of critical benefits (Miller, 1999; Blackwell et al., 2006; Althoff, 1998; Fulcher, 1998). DEX (Data Exchange Server) is usually deployed for exchanging data between suppliers and OEMs. It uses file structure to classify, organise and share any sort of data (Larrivée, 2009; Kim and Weissmann, 2006).

The PDM system encapsulates a number of automated processes to store and retrieve different types of data including metadata and geometrical data. These processes play an integral part in the collaboration process where parties invest in tooling, engineering and infrastructure (Figueiredo et al., 2008). They also participate in the projects, in the investments and design activities, acquiring rights for future sales income. That is why collaboration processes require effective validation and need to be harmonised among all business units. Process analysis can be achieved using various modelling techniques. IDEF is one of the methods to represent sequential activities using four dimensions (Cho et al., 1999; Soung-Hie et al., 2002; Lu et al., 2009). Another common standard for the exchange of product model data, STEP is a useful mechanism for harmonising and sharing heterogeneous data (Yeh and You, 2000, Tsai et. al., 2006). STEP is widely used across PLM suites and provides data exchange between enterprises. This guarantees the consistency of the product data in a manufacturing environment achieved including CAD/CAM and ERP data (Waurzyniak, 2010).

Virtual Product Management (VPM) is a software application that has a real-time possibility to display engineering data including 3D models and digital mock-up (Chi-haur et al., 2007; and Song et al., 2009). It captures data and it's re-use from the start of a new product development process. Engineers design data in a Computer-Aided Design (CAD) format. CAD is vital in creating two dimension (2D) and three dimension (3D) virtual models of products for manufacturing purposes (Shehab et. al., 2010; Zhiming et al., 2006). According to configuration management principles, data needs to be validated and 
stored in the central repository. Product Data Management Link (PDMLink) is a software application from PTC which is used to store both geometrical data and metadata. PDMLink assists the designers to store CAD files and change them if required following formal procedures (Waurzyniak, 2008; and Gao et. al., 2003)

It is necessary to utilise a control system for data retrieval to ensure that appropriate users have access to the right data. Role based access is important to exchange information and data securely across large-scale enterprises (Zhiming et al., 1999; Li et al., 2009 and Miller, 1999). Due to the use of a variety of different applications, managing data access requires significant efforts. It appears that a secure system should have both group and role based permission systems integrated. As part of the Value Stream Mapping (VSM) and Ohno's concepts, pull mode should optimise resources and processes (Chen et al., 2010 and Fawcett et al., 2010). All activities that do not add value to the product should be eliminated. To be effective, the pull system needs to be flexible and be driven from the customer who decides when and what to pull. This approach requires analysis of the processes and improvements in those areas where bottlenecks and constraints are present (Lemke, 2000).

There are various techniques used for validating and evaluating collaborative systems and tools. Cost-benefit analysis should assist in determining cost effective scenarios. It can be used for assessing project feasibility by quantifying benefits against costs. Giaglis et. al. (1999) suggested that "the nature of IS benefits are such that organizations may arrive at the need for the project through an identified need of problem solution, as a result of business process re-design, or as a strategic design".

Measuring a precise quantitative metrics is another way for assessing the efficiency of the system; the design development cycle time metric can be used to validate the efficiency of data management system for design office of small to medium size enterprise with standardized single unit production line (Storga et al., 2001).

An alternative approach (Germani et al., 2010) suggests that, instead of focusing on system-based measurements in terms of achieved time-saving and provided functionalities, qualitative benchmarking method could be utilised which allows assessing human, cognitive and communication aspects of collaboration. 
The literature review has proposed that there is a lack of research conducted on the data exchange optimisation process and methods for transferring geometrical and metadata simultaneously. In addition, there is limited evidence that pull mode systems are commonly introduced in enterprises. This research project has attempted to fill in this research gap by developing a set of recommendations to enhance the exchange process for the aerospace industry. The scope of the research is to develop a common base of understanding and knowledge for the development of scenarios.

\section{Methodology}

This section outlines a structured methodology approach employed in this project. The adopted methodology comprises seven phases as shown in Figure 2. Initially the project boundaries were defined and a number of interviews with the main stakeholders were undertaken.

An understanding of AS-IS position within the sponsoring company and confirmation of project scope were achieved and supported by a critical review. A gap analysis of the data and technology involving business and manufacturing areas was then conducted. Secure data monitoring and retrieval were defined through methodological interviews. In addition an understanding of the PDMLink system, PLM security regulations and validation process was established though stakeholder interview.

Semi-structured interviews were employed as the main vehicle for information capture. On average each interview lasted two hours, with key interviews both recorded and minuted. Software vendors, engineers, managers of architecture models and toolset development, experts in databases, servers and related software were all interviewed. Semi-structured questionnaires were prepared for these interviews. The following are examples of the questions used:

What would be an ideal situation for suppliers to access the manufacturing data?

What are the security and traceability mechanisms in PDMLink?

How is the linking mechanism between $C A D$ and metadata structured and maintained?

How can PDMLink and SharePoint be best integrated? What are the issues? 
While configuration management data is pushed from the PDM system to the file server, it is filtered in order to provide RSPs with the data that are allowed to see and use. The data provided to each RSP must be selected depending on what must be delivered to the OEM and its status for the (Tier 1, Tier 2 suppliers for example may not have the same rights). In order to remain competitive, OEMs have to protect their intellectual property and to provide external collaborators with the necessary data needed for manufacturing the components.

In order to analyse this practice, the processes have been modelled using the IDEFO technique. Figure 4 illustrates the level 2 of the process model. It enables an OEM to identify key issues in the processes described above and determine different processes in the case of implementing a new data exchange process in the company.

Many issues have been highlighted by the AS-IS model. The main issue concerns the push mode of data retrieval. This generates other issues such as the utilisation of manual processes and over processing on the OEM side. Through such a workflow, the data is duplicated in the intermediary files server which causes version control issues.

This push mode data retrieval includes manual and complex processes. These are two aspects that generate costly human errors as well as a long time for RSPs to receive the data they requested. The long lead time is particularly visible at the beginning of the collaboration process between the OEM and RSPs, and the time between the original data request and the data reception take considerable time (up to one month). Even when the collaboration process is launched, the data is not available on demand for suppliers; it is pushed on the intermediary file server during specific periods of time. These delays for suppliers to access the data reduce RSPs' ability to react quickly to any changes carried out internally by the OEM.

Feedback received from the suppliers also revealed that they access a wider range of data than they are entitled to. This means that the data retrieval security is not reliable in the current process (Figure 3). Some misunderstandings have also been observed when geometrical data and metadata are received. Such data should normally be synchronised to enable RSPs to know which metadata should apply to a specific geometry. However, this is not the case with the current systems which could lead to costly mistakes. 
On the OEM's side, issues have been identified in the current processes that need to be addressed; including harmonisation of processes at different sites and to the monitoring and tracing of data. The scenarios proposed will overcome these issues to boost the collaboration between the OEM and its RSPs. 


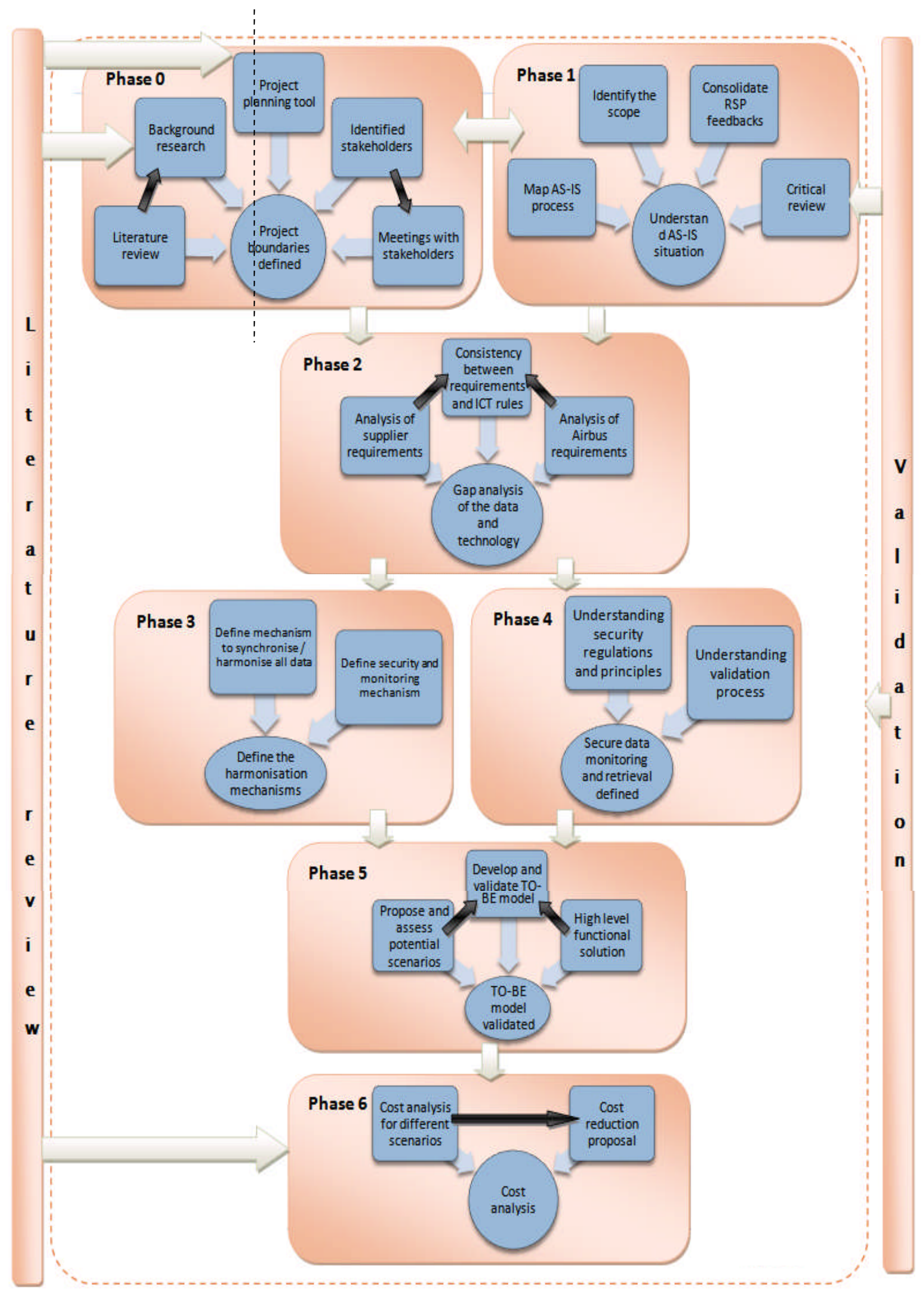

Figure 2: Research methodology adopted 


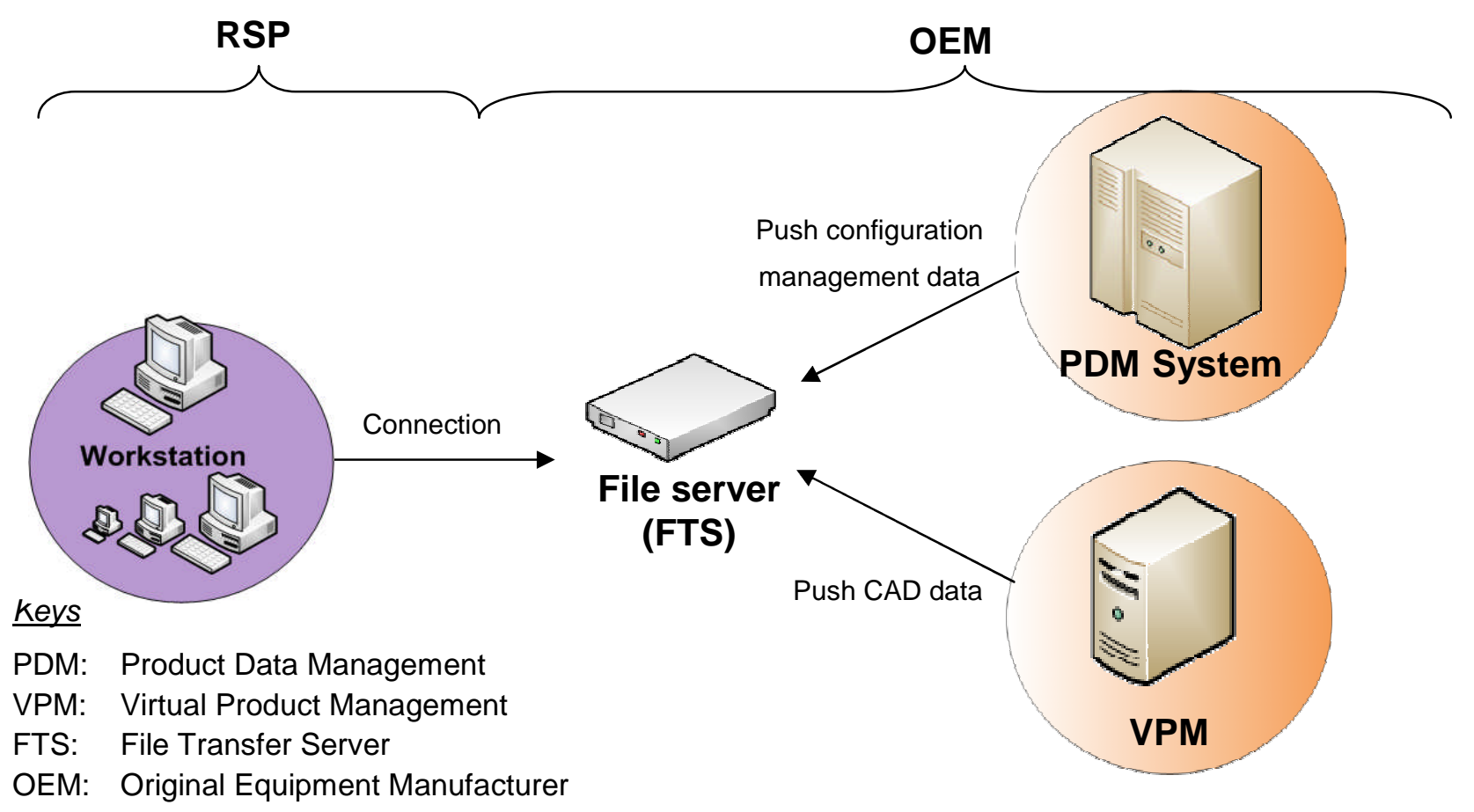

Figure 3: Current data exchange process

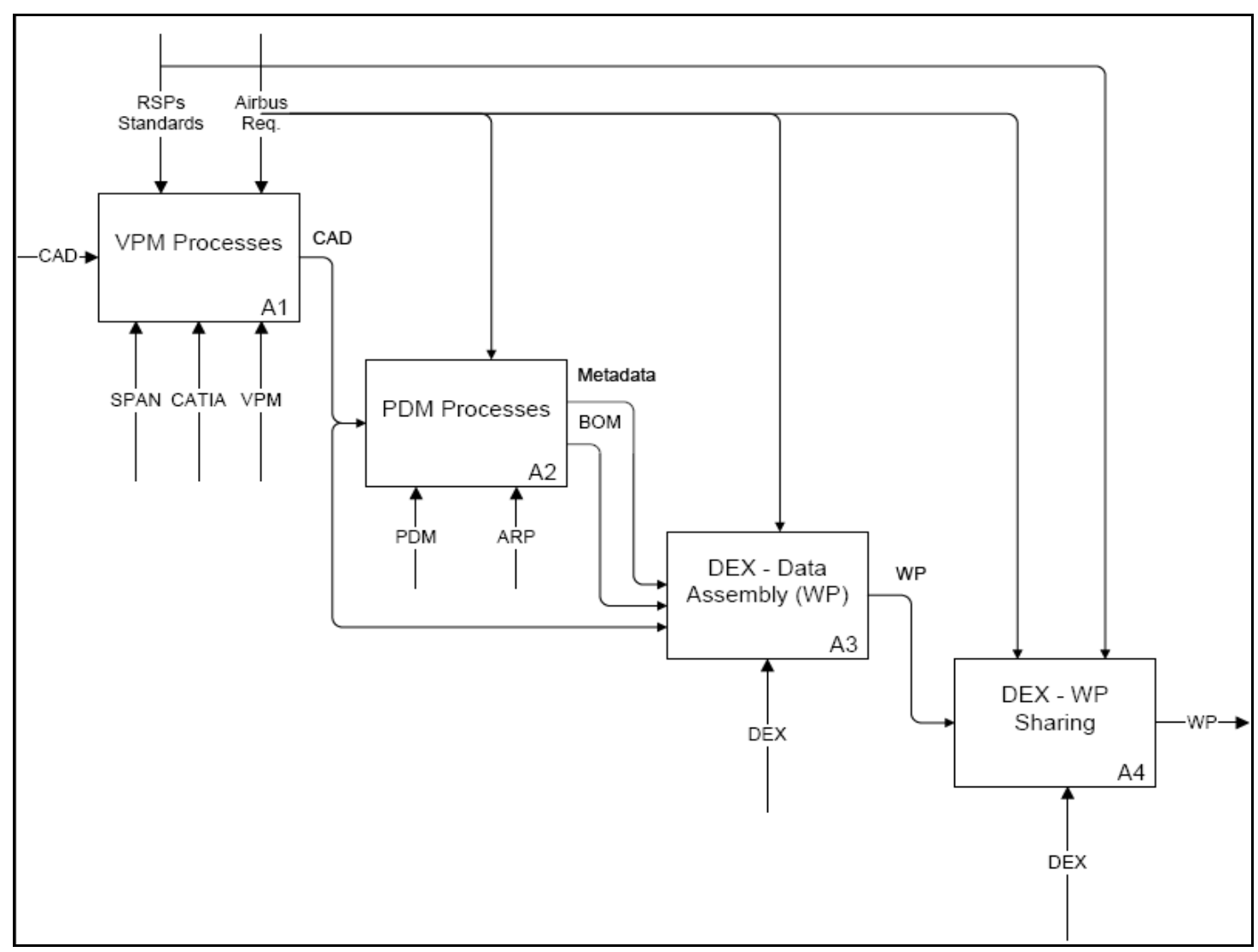

Figure 4: IDEF0 model, Level 2 


\section{Scenarios Development}

The elaboration of the different scenarios has been executed in several stages. First, it is important to understand the business requirements and then pass them to ICT for final approval. There were six concepts identified after understanding data issues, interviewing the collaborating aerospace company and completing the literature review. Further investigation unveiled that concepts can be classified by methods and scenarios. In methods, CAD data and metadata synchronisation issues were investigated. The primary objective was to enrich CAD with metadata or leave them as separate entities in the dataset folder. After careful consideration the CAD enrichment method was rejected due to the amount of customisation involved. Refining research further, there were several discussions and workshops arranged with industry specialists from PTC and OEM to understand and evaluate the options available. This resulted in the definition of four scenario solutions as shown in Figure 5.

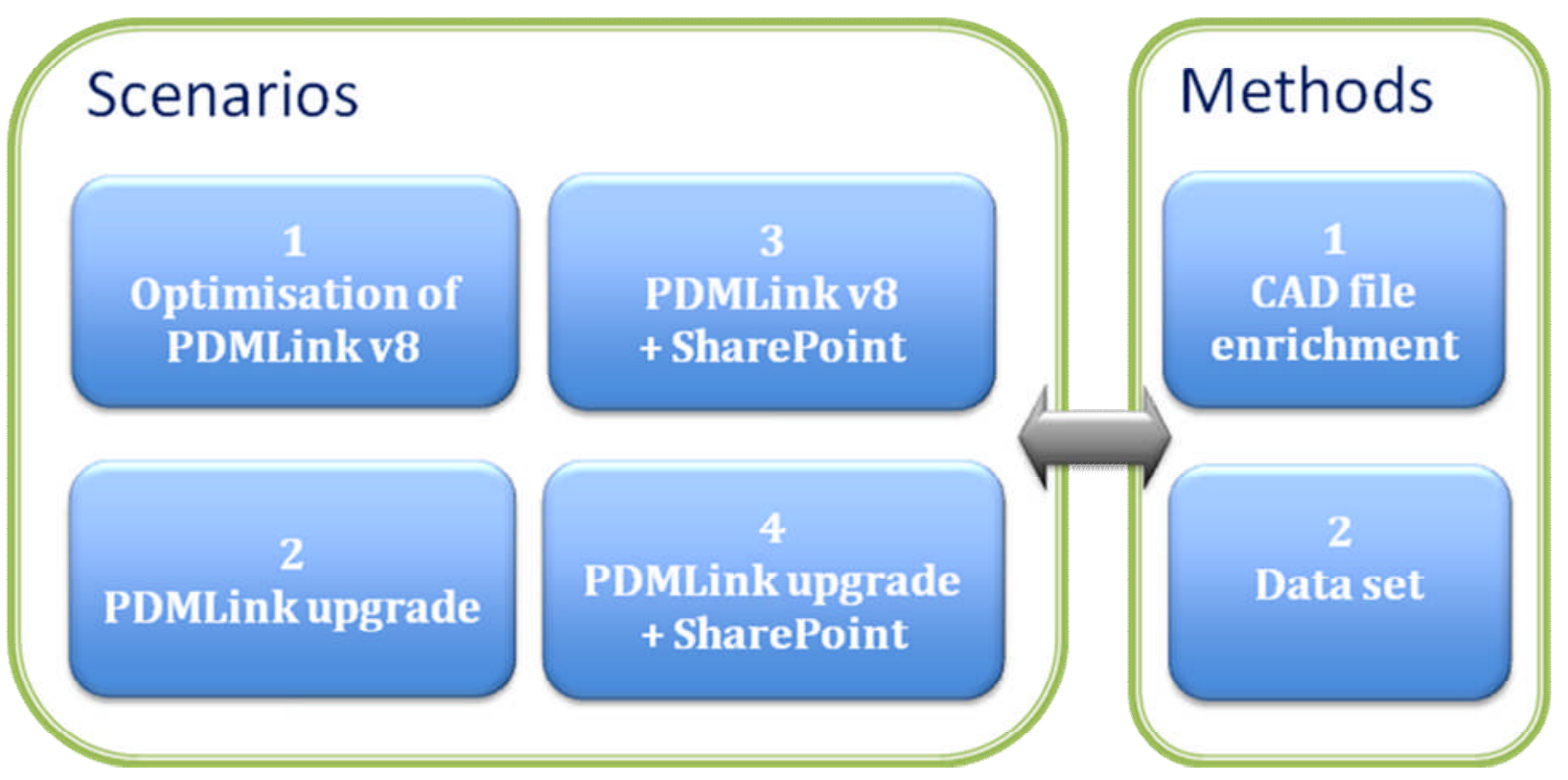

Figure 5: Scenarios elaboration 


\subsection{Description of Scenarios}

PDMLink v9.1 and SharePoint 2010 are the latest versions of the Windchill PLM system and Microsoft enterprise content management software respectively, at the time of this research. The scenarios described have been developed based on the current features of the systems.

\subsubsection{Scenario 1 - Optimisation of PDMLink v8}

This research proposes that PDMLink as a standalone solution does not satisfy a number of requirements to achieve the required product information collaboration and access between OEM and RSPs. The permission system is not flexible enough to assign RSPs to the different components of the designed item. Moreover, there is no standard method of compiling work packages for manufacturing, while data extraction from PDM follows manual or semi-automated processes with ad-hoc tools in use by OEM's. In essence, there should be three mechanisms considered in the system for successful data exchange: role based access, automated data extraction tool use and utilisation of a web based collaborative environment.

After careful investigation, it became apparent that PDMLink require optimisation of the capabilities to accommodate specified requirements. The Interactive Content Builder (ICB) is a tool that provides data extraction capabilities for RSPs. This guarantees that pull mode intention is not omitted and the data is always available on demand. In addition, there are changes in the way responsibility is allocated for pulling data. The preferred choice is to make RSPs responsible for downloading the necessary data, while user permissions and rights should be controlled using ProjectLink. this software has an enhanced permission system which is capable of granting users particular rights to specific functionality. One of the most valuable features ProjectLink offers is that RSPs can be working under the same project and being responsible for particular parts but never being able to see each other's activities in the system. It is a particularly strong advantage when suppliers are in the competition with each other. ProjectLink seamlessly integrates with PDMLink and provides a web interface allowing access to a specified project without a formal corporate authentication process. 
The optimisation approach is highly efficient in terms of causing minimum disruption to the infrastructure and leveraging existing capabilities. This should pay dividends over a relatively short period of time in comparison with other options. It is not required to redesign the entire infrastructure as with the case with MS SharePoint, data does not need to be migrated. This means that the focus is on "value adding" activities such as using ProjectLink projects for collaborative design. This should disable direct write or copy access to the OEM PDMLink central repository to prevent unauthorised downloads. Use of projectLink should also resolve security, data redundancy and integrity issues. Figure 6 illustrates the architecture.

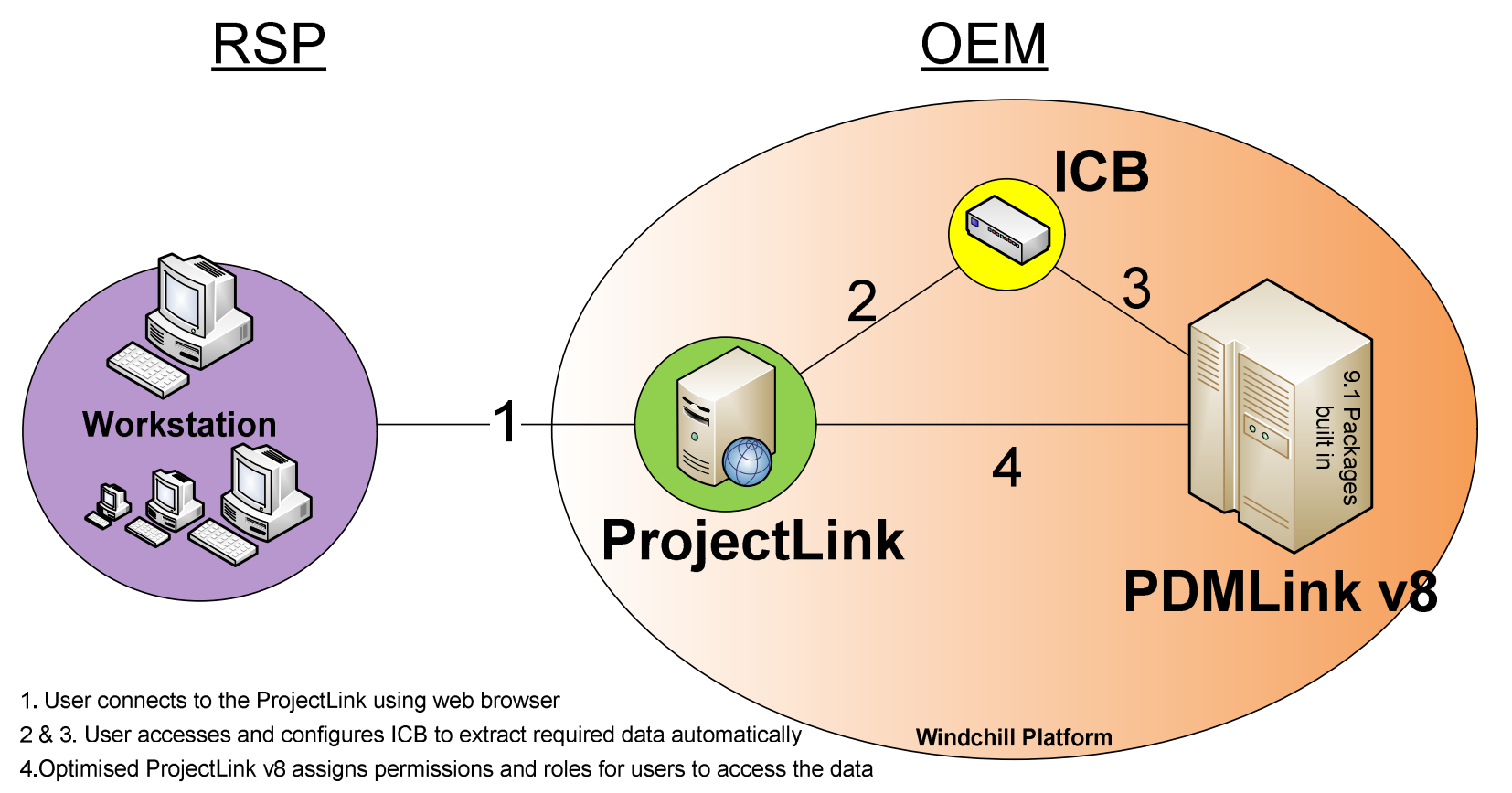

Figure 6: Architecture of scenario 1

\subsubsection{Scenario 2 - Upgrading PDMLink}

This scenario proposes a complete upgrade of the PLM system (PDMLink SSCI v8) to a new version 9.1. The Windchill PDMLink v9.1 has improved functionality in key areas including improved data synchronisation, infrastructure performance, traceability, and security. This has led to a reduction in costs and lead time for data retrieval processes.

The packages feature of PDMLink v9.1 is a new capability that allows users to create, review, distribute and track packages of Windchill managed information in the PDM system. A package can include documents, product structure, CAD files, or engineering 
changes and associated meta-data. Packages can be sent as attachments, downloaded from a link in a generated e-mail, or exported to another application off-line with the ability to view, review and trace its content. It also includes ProjectLink, which is a feature that provides role based access for RSPs, without compromising access to the whole system.

With the upgrade, product work packages could be presented using the PDMLink packages feature, with ProjectLink providing the interface for suppliers to access required data. This scenario is desirable as it extends the PDM towards suppliers, and structures the process around Windchill features that users are familiar with. However, this shall only be considered if there is the opportunity to migrate the PDM system. The upgrade should result in lower costs due to, improved performance, productivity, harmonised and simplified processes.

The advantages for this scenario include the following:

- User familiarity with the PDMLink, reducing training requirements

- Traceability, showing exactly what was delivered, received and accepted by suppliers and customers

- Better stability, scalability and increased performance of the infrastructure

- Extention of the PDM system towards suppliers

- Flexible vaulting and replication options, and simplified replication administration

However, the cost of the upgrade is high, and the risk of disruption to the current sponsoring company programme may increase. This change has to be managed well, which will require more resources. The Windchill (Vendors) road map for the new version also presents an additional time based constraint. The architecture for scenario (2) is shown in figure 7. 


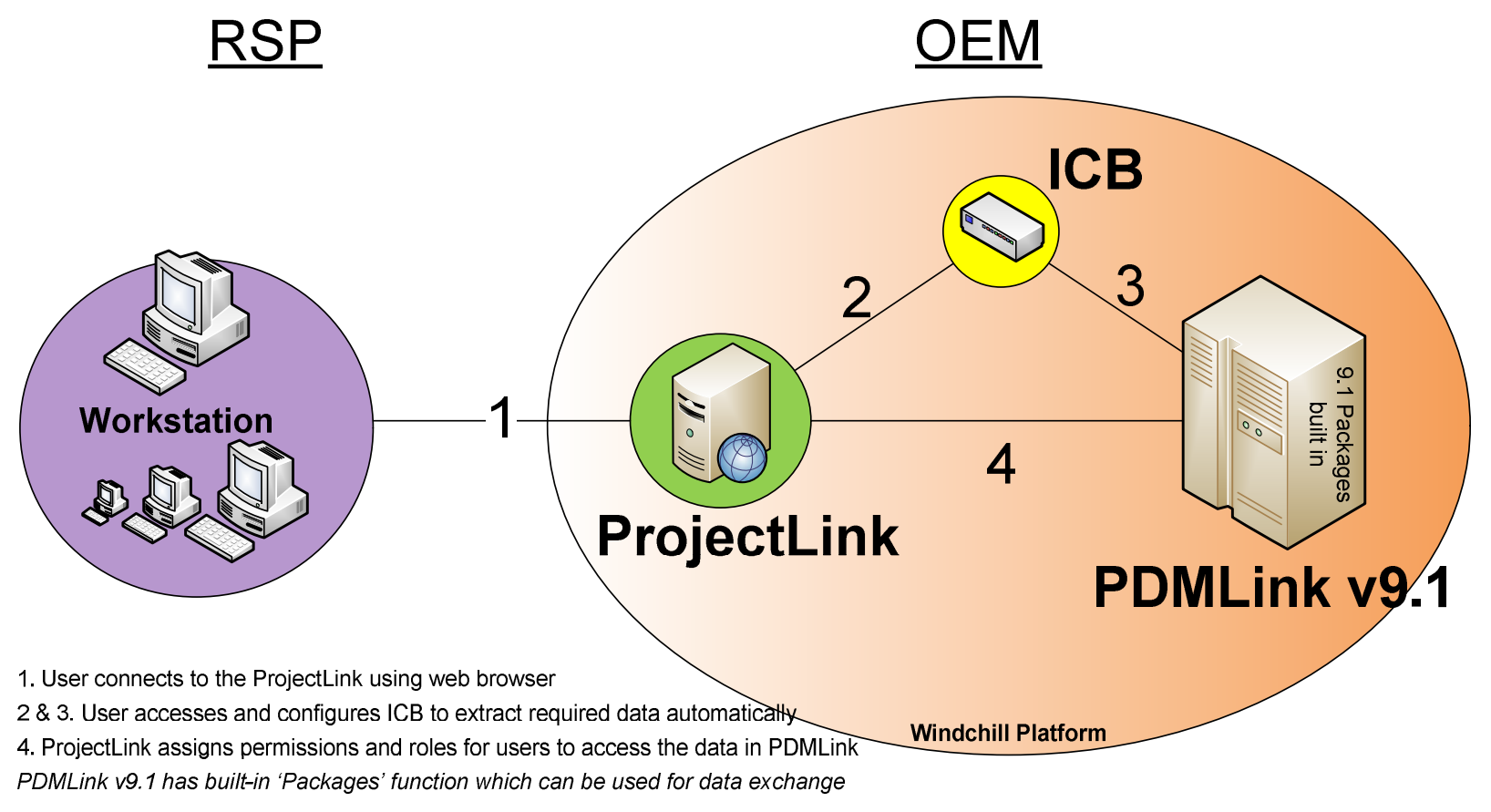

Figure 7: Architecture of scenario 2

\subsubsection{Scenario 3 - PDMLink v8 and MS SharePoint}

Microsoft SharePoint has been used as the corporate collaboration platform in different companies. The MS SharePoint 2010 has a lot of features that could be useful to achieve the objectives of data exchange process between OEM and RSPs. The document set feature of the SharePoint could be used to classify work packages, while role based mechanisms will restrict unauthorised access to the data. In addition, traceability and alert management for updates are also embedded into the standard configuration features.

This scenario offers the opportunity to integrate the current capabilities of the PDMLink v8 with SharePoint as the collaboration platform. It will also use the ICB tool (Interactive Context Builder) as a data extraction mechanism. It utilises a PDMLink Java client connected to the server, which can be used to collect the latest enterprise PDM data, through the use of a wide set of query capabilities. It assembles the required data for a product work package for each supplier, while the SharePoint platform provides a flexible web interface for RSPs to pull the data.

Windchill ProductPoint is a component that leverages MS SharePoint and PDMLink features. ProductPoint broadens the SharePoint capabilities by maintaining product structure, providing CAD support, visualising geometrical data and exchanging data with 
PDMLink. ProductPoint has key features such as the Windchill Portlets, which expose Windchill information in SharePoint, and Windchill PLM Connector used to exchange data between SharePoint and Windchill Solutions in a way that complies with configuration management.

Initial requirements suggested that for this scenario, implementation of SharePoint 2010 by the OEM is necessary. Deployment of the ICB tool should help with data extraction operations. Integration of the interface with PDMLink and the mapping processes with PDMLink are tasks that should be taken into consideration as crucial aspects of this scenario, in addition role based security mechanisms should be put in place to ensure a secure data retrieval process by RSPs.

The advantages of MS SharePoint include a comprehensive workflow engine which is widely used for sharing and tracking purposes. The graphical user interface also provides flexible navigation and is very intuitive, providing a shortened learning curve due to familiar MS environment. MS SharePoint can be used by suppliers as it is possible to integrate information from other sources like SAP and Siebel in one place, the software also provides ability to complement existing implementations of Windchill product lifecycle management solutions.

One of the disadvantages is that deployment may take longer to implement due to the complexities of both the software and the management of security permissions, which must be completed in PDMLink and SharePoint. Current RSP processes will require major modifications to work efficiently in the new environment. Although the Product Point interface works only with PDMLink v9.1, it is possible to create an interface with v8, using an intermediate database (with data structures from v9.1). This will have implications fordata synchronisation, duplication, cost and complexity. In addition, the deployment will have cost implications including hardware upgrades and software licenses. This may also trigger increases in total cost ownership for support and future upgrades. Any modifications should be carefully considered from a project management perspective. Figure 8 presents the architecture of scenario (3). 


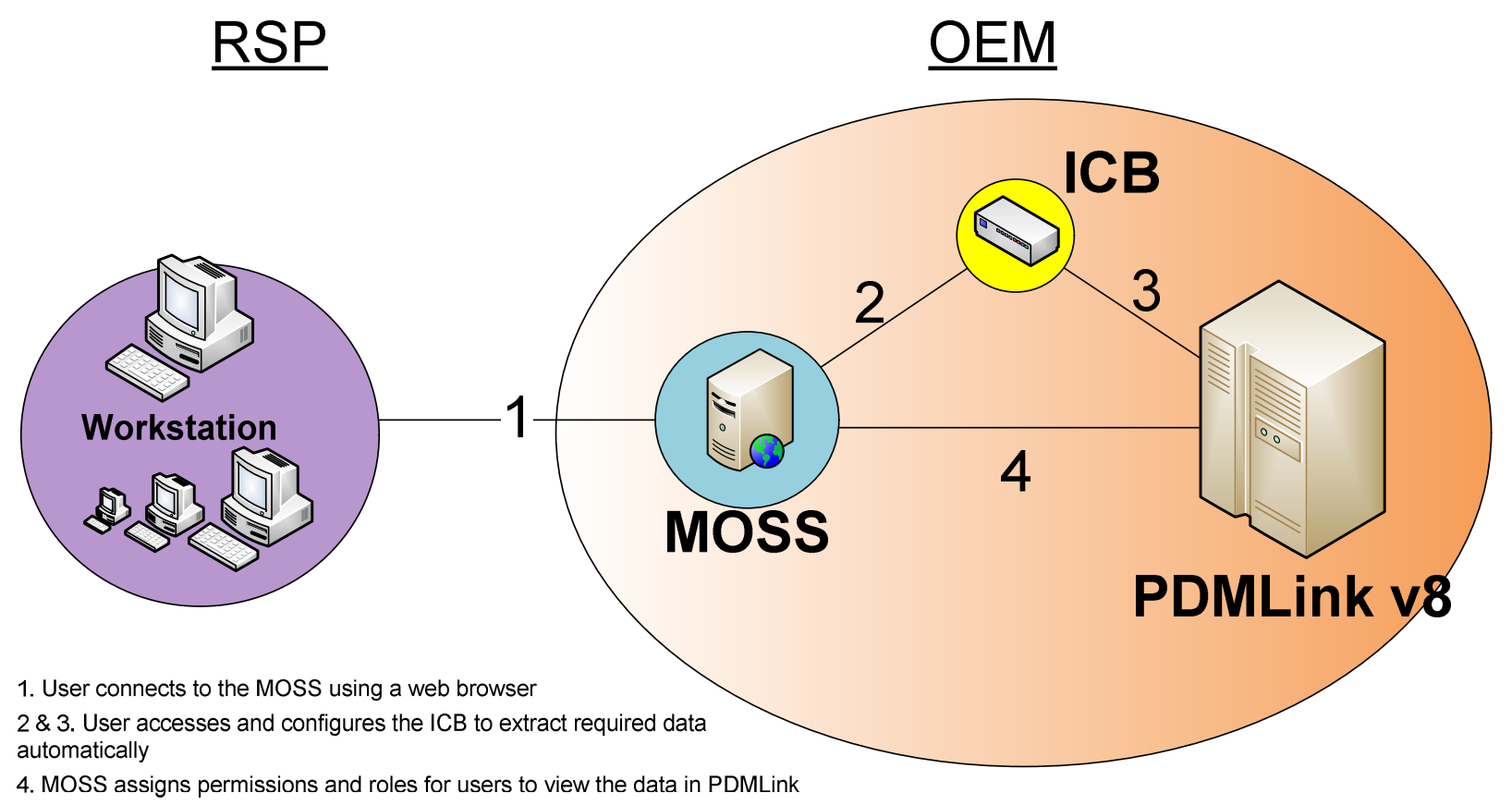

Figure 8: Architecture of scenario 3

\subsubsection{Scenario 4 - PDMLink upgrade and MS SharePoint}

This scenario proposes a combination of MS SharePoint 2010 with the new version of PDMLink v9.1. The scenario utilises SharePoint (currently implemented within the company as a corporate content management and collaboration solution) alongside feature set of PDMLink v9.1 as highlighted in the previous scenario.

To aid this, PDMLink v9.1 has a native interface with SharePoint for easy and natural integration, via the Windchill WebParts for SharePoint,. This provides robust integration with the PLM so that users can access product information without compromising the PLM data structures. It also leverages existing SharePoint infrastructure to extend the PLM capabilities and achieve the aims of this project.

The combination of using PDMLink v9.1 features like the ICB tool, packages, and utilising the web parts and ProductPoint, to provide integration with SharePoint 2010 capabilities, will provide a robust solution that meets all required objectives.

Implementing this scenario would require SharePoint 2010, an upgrade to PDMLinkv9.1, and system integration. 
The advantages of this scenario include a user friendly and up to date graphical user interface. This is due to the fact that SharePoint provides an integrated, intuitive and customisable interface ifor suppliers. It will also be easier to harmonise and standardise processes across the organisation using the same platform. By leveraging the existing SharePoint workflow engine, product information can be shared and tracked by both suppliers and extended product development teams.. This scenario provides a robust integration between a best-in-class PLM and the SharePoint collaboration platform.

In terms of drawbacks this scenario requires more effort, longer implementation time, and increased costs with the need for new software licenses and hardware resources. It will also require major process changes and disruption to the current programme. The overview of the architecture for this scenario is shown in Figure 9.

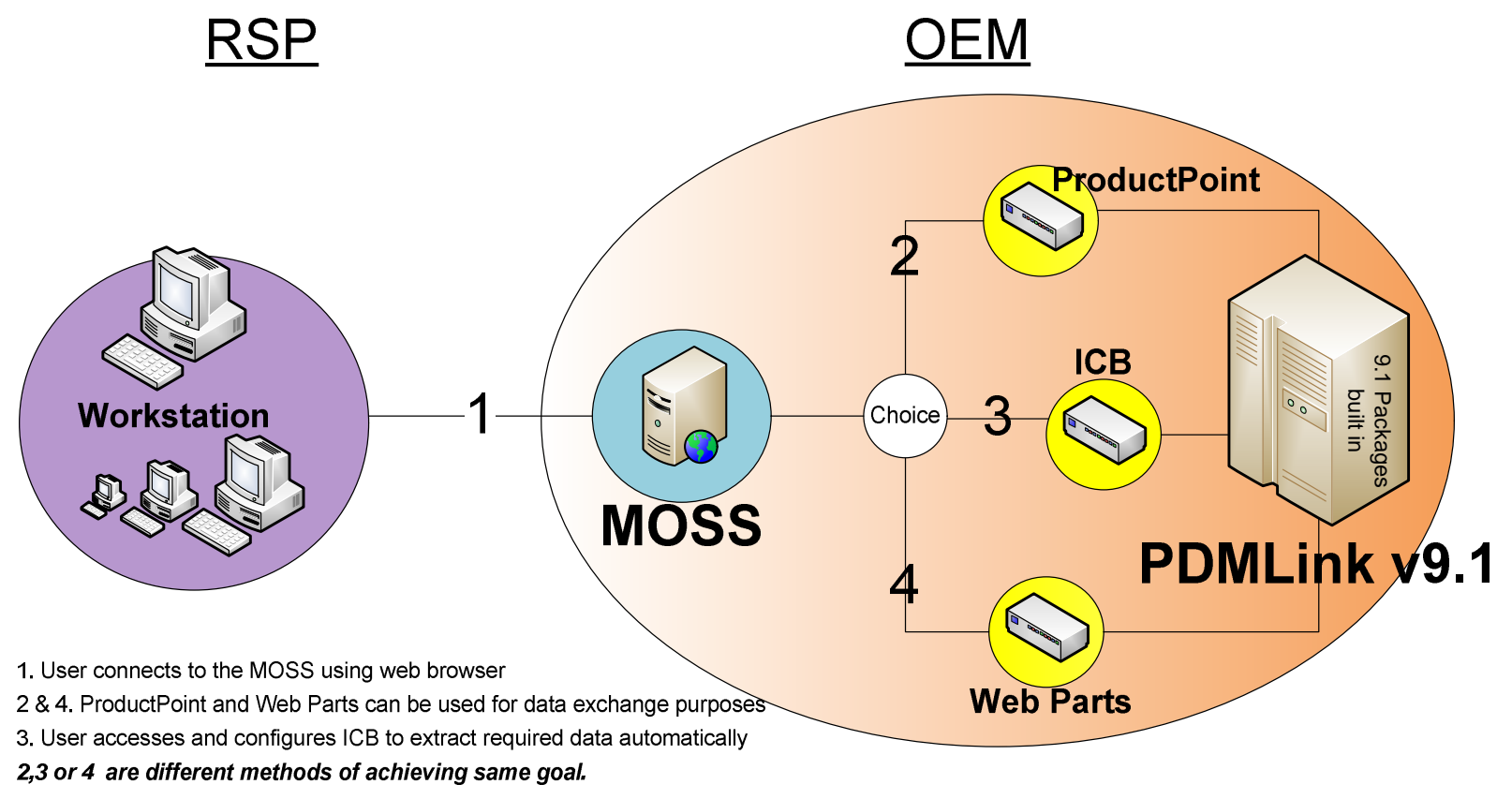

Figure 9: Architecture of scenario 4

\subsection{Alternative scenarios ranking}

Once the scenarios had been developed, it was crucial to compare them in an objective way in order to determine the most feasible option. Therefore, a list of criteria and relative weights has been identified (with reference to their importance for this research project as well as OEMs' policy). 
It was important to identify the criteria that will meet the business objectives of this research project, and tally with the corporate goals of the enterprise. These criteria, weights and scores have been validated by the OEM project manager as well as external experts from PTC (the providers of PDMLink), involved in both the technical and cost aspects.

The criteria, represented in Table 2, take into account major elements from technical aspects to the OEM organisational constraints and measures. Business Value is a measure that shows the ability of the solutions to provide the full set of functionalities required, such as traceability and/or creation of product work packages.

Another measure that was considered is the Constraints Compliancy which defines the amount and strength of external constraints that the scenario will have to overcome during implementation. Furthermore, 'Processes Impacted' depicts the relative quantity of changes in processes that will occur as a consequence of implementing the scenario.

In addition the Graphical User Interface measure allows for the evaluation of the solution in terms of interface usability. The Support and Maintenance measure indicates the relative complexity and cost required for the support and maintenance of the new solution. Architecture Value is an important criterion assessing the complexity of the scenario from the architecture prospective, and considers the complexity of interactions between systems.

The Deployment Cost, measures the cost required including costs associated with implementation, integration and training. The Security Value criterion assesses the ability of the solutions to provide secure role based access to suppliers, and the protection of OEMs' data. Licensing Cost evaluates the impact of extra costs involved in the implementation of the solutions in terms of licences due to upgrades and customisation. Finally, Compliance with Long term strategy appraises the capability of each solution to be aligned with long term ICT strategy of OEM.

The identification of the scenarios ranking was a long process developed through a brainstorming exercise conducted by both the research team and the project manager. Workshops were then held with the involvement of PTC experts. All the stakeholders defined a final set of criteria (the criteria stated previously). Subsequently, relative weights 
were assigned to the criteria to indicate their importance. Three levels have been selected - from one (low) to three (high). The compliance to the criteria was allocated based on a scale from one (weak) to five (excellent). Table 2 shows the ranking of the achieved scenario.

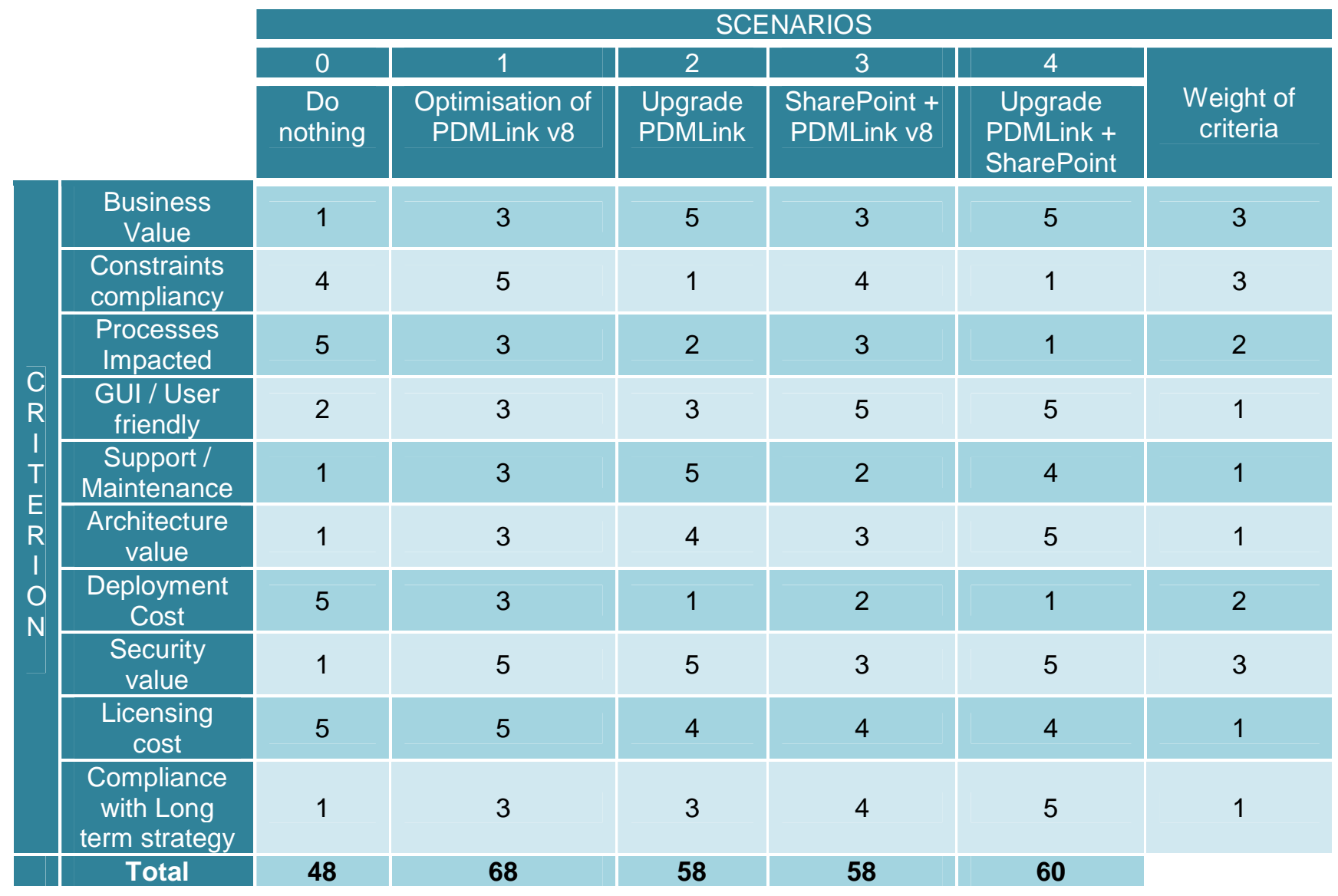

Table 2 Ranking matrix with scores

\section{Validation}

Throughout this study, that has been carried out with Airbus (UK), every deliverable and method used has been validated carefully and systematically in order to deliver reliable results and recommendations. However as this study is located at the early stage of the project, the validation completed has been mainly qualitative in nature. An overview of validation activities is shown in Table 3.

The interviews were recorded and last, on average, for two hours each. The interviews and meetings minutes have been written down systematically from these records and have been validated by at least one team member in the case of a simple interview and by the interviewee or by the project leader of the sponsoring company for more complex cases. 
Specific validations have been completed at each stage of the project. It was crucial to have a solid understanding of the current situation within the OEM Company before proposing new alternatives for data exchange. Therefore it was necessary to engage a range of interviewees: a number of interviewees had a general understanding of the overall data exchange with suppliers while others had more specific and deeper information on specific areas such as suppliers requirements or technologies involved. This understanding, and the IDEFO AS-IS model created from it have been validated with the OEM project leader, the head of manufacturing collaboration and experts in the technical areas involved. This validation was facilitated through a workshop and a set of short interviews.

The second deliverable was a Business Requirement Dossier (BRD) which gave a detailed description of the solution requirements. The requirements have been determined from interviews and a first version of this document has been validated by the interviewees through one hour meetings (with several iterations) and sent for further validation to key business stakeholders involved in security, architecture, and technology and manufacturing areas.

Defining and selecting viable solutions to fulfil the requirements has been a complex process including many iterations not only with the project leader of the sponsoring company, but also with experts from PTC (the company providing the data management system currently used by the OEM) and CATIA V5 experts from Dassault Systems (provider of CAD file enrichment methods). This close collaboration with experienced people has enabled the building of realistic business cases for several potential solutions. The use of interviews, phone calls and a full day workshop session with the experts involved on the technology and cost aspects has also added additional weight to the scenarios.

A ranking matrix with objective criteria has been created to rank the scenarios. This has been completed in two stages. First the criteria and weights were validated by all parties through interviews. Then the project team met the experts and the project leader independently to discuss their scores and reach an agreement via a workshop. Consequently the recommendations that are provided in this document have been validated by technical experts as well as experienced company representatives. 


\begin{tabular}{|c|c|c|c|}
\hline Validation activity & Benefits & Improvements & Limitations \\
\hline $\begin{array}{l}\text { Semi-structured } \\
\text { interviews for } \\
\text { understanding AS- } \\
\text { IS processes }\end{array}$ & $\begin{array}{l}\text {-Provide a base to } \\
\text { understand current } \\
\text { processes }\end{array}$ & $\begin{array}{l}\text {-Industrial and academic validations } \\
\text { enabled improvement of the AS-IS } \\
\text { process model to reflect the issues }\end{array}$ & $\begin{array}{l}\text {-Some of the } \\
\text { activities are not } \\
\text { fully documented }\end{array}$ \\
\hline $\begin{array}{l}\text { Workshop and } \\
\text { semi-structured } \\
\text { interviews to } \\
\text { validate the } \\
\text { business } \\
\text { requirements }\end{array}$ & $\begin{array}{l}\text {-Capture desired } \\
\text { requirements to enable } \\
\text { development of the right } \\
\text { solution } \\
\text {-Confirm all necessary } \\
\text { requirements have been } \\
\text { included }\end{array}$ & $\begin{array}{l}\text {-The requirements were tailored to } \\
\text { be specific to the needs of users } \\
\text {-Confirmed expectations of users } \\
\text { have been included } \\
\text {-Classifies requirements into } \\
\text { mandatory and optional } \\
\text { requirements }\end{array}$ & $\begin{array}{l}\text {-Some special } \\
\text { requirements that } \\
\text { require different } \\
\text { processes cannot } \\
\text { be included } \\
\text {-Requirements } \\
\text { could change } \\
\text { during or before } \\
\text { implementation is } \\
\text { completed }\end{array}$ \\
\hline $\begin{array}{l}\text { Workshop to } \\
\text { validate developed } \\
\text { scenarios }\end{array}$ & $\begin{array}{l}\text {-Confirm that scenarios } \\
\text { are technically feasible } \\
\text {-Highlight the business } \\
\text { constraints }\end{array}$ & $\begin{array}{l}\text {-Industrial and expert validations } \\
\text { enabled the scenarios to be } \\
\text { improved } \\
\text {-Additional ideas used to improve } \\
\text { the scenarios } \\
\text {-Confirmed the feasibility of } \\
\text { implementing the scenarios }\end{array}$ & $\begin{array}{l}\text {-The result is based } \\
\text { upon current } \\
\text { technologies } \\
\text { available } \\
\text {-The scope was } \\
\text { reduced to consider } \\
\text { only tools within the } \\
\text { client environment }\end{array}$ \\
\hline $\begin{array}{l}\text { Workshop to } \\
\text { validate ranking of } \\
\text { scenarios }\end{array}$ & $\begin{array}{l}\text {-Enables the selection of } \\
\text { the right criteria - } \\
\text { Normalise scores based } \\
\text { on previous experience } \\
\text { and prevailing situations } \\
\text {-Use expert knowledge } \\
\text { to objectively compare } \\
\text { the scenarios }\end{array}$ & $\begin{array}{l}\text {-Industrial validation enabled the } \\
\text { criteria selected to be adjusted with } \\
\text { the right weighting to reflect relative } \\
\text { impact on business } \\
\text {-The expert advice provided } \\
\text { appropriate scores for the } \\
\text { scenarios } \\
\text {-The result reflects the business } \\
\text { and technical needs, and it was } \\
\text { agreed by the experts and users }\end{array}$ & $\begin{array}{l}\text {-Focus was more } \\
\text { on internal } \\
\text { constraints }\end{array}$ \\
\hline
\end{tabular}

Table 3 Overview of validation

\section{Research Benefits and Discussion}

The implementation of this new pull mode data retrieval process should bring multiple benefits to the OEM. The automation of the process should lead to better utilisation of resources and the removal of manual processes related to the push mode process. The data management quality should also be improved. Allowing RSPs to retrieve manufacturing data directly from the OEM system would avoid duplication of data and enable suppliers to retrieve up to date information. The data would be available on demand for suppliers whereas previously they had to wait for the data to be pushed on the intermediary file server at specific times. Consequently the overall data exchange lead time would reduce significantly. 
A key benefit of the new data exchange processes proposed in this research would be the protection of the OEM's intellectual property. They offer comprehensive role based access mechanisms that would enable OEMs to efficiently restrict the access to their databases.

In the case of Airbus, where different data exchange processes are used depending on the country a particular corporate division operates in; implementing the new solution would also be a way of harmonising the processes throughout the company.

The PDMLink based scenarios reinforce the solutions using the PLM system, and restrict all other requirements to be provided within the boundaries of the system. While this could provide the benefit of using a single system, simplifying security and support issues to a single system, it places more burdens on software vendors to meet increased demands for additional functionality to satisfy increasing requirements.

Extending the SharePoint interface with other groups enhances the PLM collaboration capabilities, providing supplementary gains such as, trouble-free access, multiple usage of collaboration systems and a greater return on the investment. Possible drawbacks may include more stringent security measures to manage multiple systems and additional interface complexity, which might increase the total cost of ownership.

From trends observed in organisations, interlinkage with suppliers, partners and customers is the norm; along with multinational manufacturing operations involving geographically dispersed entities with a requirement to share data in real time. This provides a strong case for more collaboration in the product lifecycle management system in order to operate efficiently and competitively.

Since organisations realised the importance of information as a corporate asset, most now implement a solution for enterprise content management platform to achieve collaboration and manage information. The PLM vendors have also improveed the collaboration capabilities of their systems with each new release to make them more compatible with the business. It is obvious that a lot of benefit could be realised by having the same system achieve both functions. While the future might ultimately lead to a single one stop solution, it could be worthwhile for OEMs to consider solutions that enable secure data access and collaboration when planning for new PLM or ECM systems. 
In highly specialised sectors, where design data is paramount, effective data access is required. To achieve this, there should be a collaborative system to interface the OEMs and their suppliers. The scenarios described in this paper can be viewed as enabling this based on the constraints that are prevalent at any stage. For a new project, the solution could be developed in the concept stage, and the identified PLM solution could be implemented with the collaboration capabilities to achieve effective pull mode access. For a running programme, timing is crucial as the disruptions caused by switching to a new system must be weighed against expected benefits. It is usually very difficult to achieve this without incurring substantial costs. Hence, it is more practical to confine the solution within the boundary of current systems and use available tools to meet the objectives.

The pull mode solution for data access provides several benefits that could be of immense value to organisations. It could provide a competitive edge,lowering the cost by reducing complexity. It also enables suppliers to pull data when it is required, thereby speeding up manufacturing and improving efficiency. Data quality is improved because information can be filtered and refined to fulfil manufacturing requirements; eliminating data duplication, enhancing data consistency and reducing the chance of mistakes.

\section{Conclusions}

This paper presents various technical solutions which affect the interaction between OEM and their tier-one suppliers. In recent years, tier one suppliers have become Risk Sharing Partners (RSPs) by being involved in both the design and manufacturing processes. This requires suppliers to be tightly integrated into the corporate processes of the OEMs, and prompting the re-configuration of corporate systems to ensure that they can play a vital role in design and manufacturing activities.

Vast amounts of geometrical (CAD) design data and metadata are produced during the PLM lifecycle, which needs to be managed. The PLM strategy therefore depends on the information systems strategy, and collaboration with RSPs requires sophisticated control mechanisms which must guarantee compliancy with corporate strategy; traceable, effective and reliable data exchange methods and on demand data pulling processes. These requirements can only be achieved with a strong PDM system utilising several permission layers to enable supplier access data and collaboration within virtual workspaces using role based access. 
This research concluded that efficient synchronisation of geometrical design data and Metadata have a significant impact on manufacturing activities, and a pull mode solution for manufacturing data access will provide OEMs with an efficient solution for collaboration with suppliers.

Four scenarios were proposed utilising a combination of PTC PDMLink and Microsoft SharePoint technologies. These were analysed and validated, and the best option based on the prevailing constraints was presented.

The main benefits that could be realised are a reduction in lead time required to obtain manufacturing data from the PLM, an improvement in security and the elimination of manual processes. This research will also enable both OEMs and suppliers to benefit from lean processes, while reducing costs and improving harmonisation of processes. Additional research is required to further explore the integration of collaboration tools and PLM systems; an approach which could well be the future facilitator of interactions between OEMs and suppliers.

\section{Acknowledgments}

The authors would like to thank Airbus Operations Ltd., UK, for funding this research project. We would also like to express our appreciation to Airbus and PTC employees for their effort and Dr. Chris Turner at Cranfield University for his time in reviewing the manuscript.

\section{References}

Abramovici M. and Sieg, O.C. (2002), "Status and development trends of product lifecycle management systems", Proceedings of the IPPD, Wroclaw, Poland.

Althoff, J. (1998), "Understanding the roles of CSM, PDM, and ERP in product development", Electronic Design [H.W.Wilson - AST], vol. 46, no. 6, pp. 82-84.

Baker, P. (1999), "PDM--what do you need to know?", Works Management, vol. 52, no. 5, pp. 25-26. 
Blackwell, P.; Shehab, E. M.; Kay, J. M. (2006), "An effective decision-support framework for implementing enterprise information systems within SMEs", International Journal of Production Research, vol. 44, no. 17, pp. 3533-3552.

Bouna, B. A.; Chbeir, R.; Marrara, S. (2009), "Enforcing role based access control model with multimedia signatures", Journal of Systems Architecture, vol. 55, Issue 4, pp. 264274.

Chen, J. C.; Li, Y.; Shady, B. D. (2010), "From value stream mapping toward a Lean / Sigma continuous improvement process: an industrial case study", International Journal of Production Research, vol. 48, Issue 4, pp. 1069-1086.

Chi-haur, W.; Yujun, X.; Swee, M. M. (2007), "Linking product design in CAD with assembly operations in CAM for virtual product assembly", Assembly Automation, vol. 27 Issue 4, pp. 309-323.

Cho, H.; Lee, I. (1999), "Integrated framework of IDEF modeling methods for structured design of shop floor control systems", International Journal of Computer Integrated Manufacturing, vol. 12 Issue 2, pp. 113-128.

Fan, L.Q.; Senthil Kumar, A.; Jagdish, B.; Bok, S. (2008), "Development of a distributed collaborative design framework within peer-to-peer environment", Computer- Aided Design, vol. 40, Issue 9, pp.891-904.

Fan, L.Q.; Zhu, H.B.; Bok, S.H.; Senthil Kumar, S.A. (2007). "A framework for distributed collaborative engineering on grids". Computer-Aided Design and Applications, vol. 4, pp. 353-362.

Fawcett, S. E.; Fawcett, A. M. (2010), "The PB\&J Challenge: Using Value-Stream Mapping to Drive Learning Loops", Decision Sciences Journal of Innovative Education, vol. 8 Issue 1, pp. 257-268.

Figueiredo, P.; Silveira, G.; Sbragia, R. (2008), "Risk Sharing Partnerships with Suppliers: the Case of Embraer", Journal of Technology Management \& Innovation, vol. 3, no. 1, pp. 27-37. 
Frillman, S. A.; Wilde, K. L.; Kochert, J. F.; Homan, S. R.; Tomovic, C. L. (2010), "Entrylevel engineering professionals and Product Lifecycle Management: a competency model", International Journal of Manufacturing Technology \& Management, vol. 19 Issue 3/4, pp. 306-311.

Fulcher, J. (1998), “A common vision”, Manufacturing Systems (MSI), vol. 16 Issue 8, pp. 36-40.

Gao, J. X.; Aziz, H.; Maropoulos, P. G; Cheung, W. M. (2003), "Application of product data management technologies for enterprise integration", International Journal of Computer Integrated Manufacturing, vol. 16, no. 7-8, pp. 491-500.

Germani, M.; Mengoni, M.; Peruzzini, M. (2010), "A method to define a co-design platform to support cooperative work in SMEs", Proceedings of International Conference on Product Lifecycle Management, pp. 451-46, 6-8 July, Bath, UK.

Giaglis, G. M.; Nikolaos M; Georgios I. D. (1999), "The ISSUE methodology for quantifying benefits from information systems", Logistics Information Management 12.1-2 50-62. EJournals.

Kim, S.; Weissmann, D. (2006), "Middleware-based Integration of Multiple CAD and PDM Systems into Virtual Reality Environment", Computer-Aided Design and Applications, vol. 3, no. 5, pp. 547-556.

Larrivée, Y. (2009), "Hot metal transport: A MES role in inter-sector data exchange", Aluminium International Today, vol. 21 Issue 5, pp. 17-18.

Lemke, J. (2000), "VPDM (virtual product development management) is replacing PDM", Design News, vol. 55, no. 8, pp. 144-145.

Li, Q.; Zhang, X.; Xu, M.; Wu, J. (2009), "Towards secure dynamic collaborations with group-based RBAC model", Computers \& Security, vol. 28, no. 5, pp. 260-275.

Lu, M.; Liao, S. (2009), "An integrated IDEF0-3/CTPN/SFC approach for design and analysis of discrete event control systems", International Journal of Production Research, vol. 47, Issue 22, pp. 6433-6453. 
Masood, A.; Bhatti, R.; Ghafoor, A.; Mathur, A. (2009), "Scalable and Effective Test Generation for Role-Based Access Control Systems", IEEE Transactions on Software Engineering, vol. 35, Issue 5, pp. 654-668.

Miller, E. (1999), "Integrating PDM and ERP", Computer - Aided Engineering, vol. 18, no. 3, pp. 69-70.

Müldner, T.; Leighton, G.; Miziołek, J. K. (2009), "Parameterized Role-Based Access Control Policies for XML Documents", Information Security Journal: A Global Perspective, 2009, vol. 18 Issue 6, pp. 282-296.

Rosen, J. (2010), "Product lifecycle management and you", Industrial Engineer, vol. 42 Issue 1, pp. 44-49.

Shehab E M, Bouin-Portet M, Hole R and Fowler C. (2010) "Enhancing of Digital Design Data Availability in the Aerospace Industry" CIRP Journal of Manufacturing Science and Technology, vol. 2, Issue 4, pp. 240-246.

Shen, W.; Hao, Q.; Li, W. (2008), "Computer supported collaborative design: Retrospective and perspective", Computers in Industry, vol. 59, Issue 9, pp. 855-862

Song, I.; Chung, S. (2009), "Synthesis of the Digital Mock-up System for Heterogeneous CAD Assembly", Computers in Industry, vol. 60, Issue 5, pp. 285-295.

Soung-Hie K.; Ki-Jin J. (2002), "Designing performance analysis and IDEF0 for enterprise modelling in BPR", International Journal of Production Economics, vol. 76, Issue 2, pp. 121-133.

Storga, M.; Pavlic, D.; Marjanovic, D. (2001), "Reducing Design Development Cycle by Data Management Within the Design Office", Proceedings of the $13^{\text {th }}$ International Conference On Engineering Design - ICED 01, 21-23 August, Glasgow,UK.

Tomovic, C. L.; Ncube, L. B.; Walton, A.; Grieves, M. (2010), "Application of PLM in higher education procurement", International Journal of Manufacturing Technology \& Management, vol. 19, Issue 3/4, pp. 167-179. 
Tsai C-Y, Sun T-H and Huang J-X (2006), "A web-based XML information sharing system for collaborative product development" International Journal of Production Research, vol. 44, no. 15, pp. 2955-2976.

Waurzyniak, P. (2008), "PLM Tools Speed Developments", Manufacturing Engineering, vol. 140 Issue 6, pp. 101-108.

Waurzyniak, P. (2010), "CAD/CAM Software Drives Innovation", Manufacturing Engineering, vol. 144 Issue 2, pp. 49-55.

Yeh, S.; You, C. (2000), "Implementation of STEP-Based Product Data Exchange and Sharing", Concurrent Engineering: Research and Applications, vol. 8, no. 1, pp. 50-60.

Zha, X.F.; Du, H. (2006), "Knowledge-intensive collaborative design modelling and support. Part I. Review, distributed models and framework", Computers in Industry, vol. 57, Issue 1, pp. 39-55

Zhiming, Q.; Jerry, Y. H.; Yoke, S. W. (2006), "Secure CAD Model Retrieval and Data Consistency: Issues in Role-based Visualization", Computer-Aided Design and Applications, vol. 3, no. 1-4, pp. 139-144. 